$10-6-2005$

\title{
Nicholas Reactions with Carboxylic Acids for the Synthesis of Macrocyclic Diolides
}

Kevin M. Shea

Smith College, kshea@smith.edu

Kristina D. Closser

Miriam M. Quintal

Follow this and additional works at: https://scholarworks.smith.edu/chm_facpubs

Part of the Chemistry Commons

\section{Recommended Citation}

Shea, Kevin M.; Closser, Kristina D.; and Quintal, Miriam M., "Nicholas Reactions with Carboxylic Acids for the Synthesis of Macrocyclic Diolides" (2005). Chemistry: Faculty Publications, Smith College, Northampton, MA.

https://scholarworks.smith.edu/chm_facpubs/9 


\section{Nicholas Reactions with Carboxylic Acids for the Synthesis of Macrocyclic Diolides}

Kevin M. Shea, ${ }^{*}$ Kristina D. Closser, and Miriam M. Quintal

Department of Chemistry, Smith College, Northampton, Massachusetts 01063

kshea@email.smith.edu

RECEIVED DATE (to be automatically inserted after your manuscript is accepted if required according to the journal that you are submitting your paper to)

Abstract

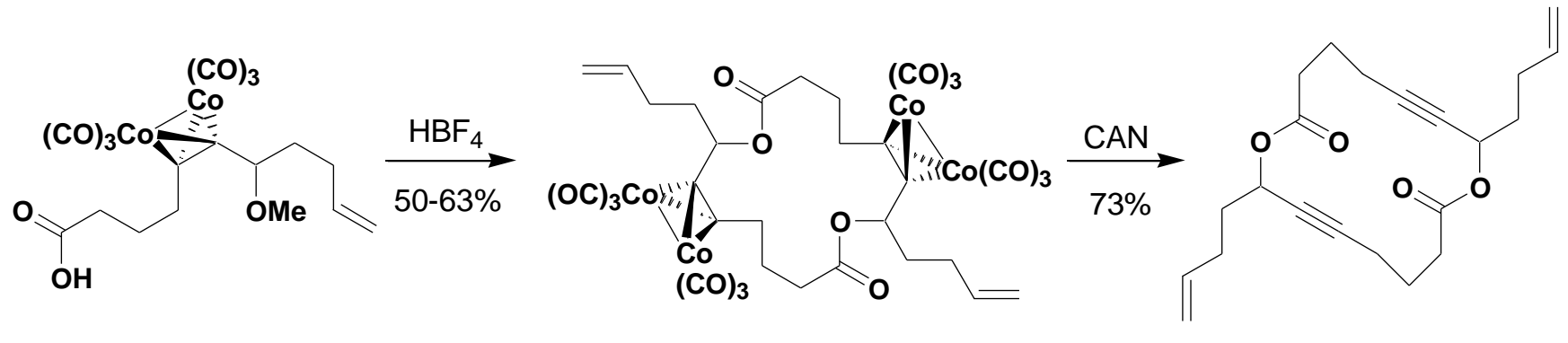

We have developed a new strategy for the preparation of diolides using a cascade of Nicholas reactions. The carboxylic acid nucleophiles in these reactions are virtually unstudied participants in transformations of this type. Using this methodology, a sixteen-membered cobalt-complexed cyclic diyne is available in $28 \%$ yield over eight steps (an average of $85 \%$ per step). We can also easily access the uncomplexed diolide in one additional step. 
In connection with our recently disclosed methodology involving tandem intramolecular Nicholas and Pauson-Khand reactions for the synthesis of tricyclic oxygen-containing heterocycles, ${ }^{1}$ we decided to investigate an extension of this strategy for the synthesis of tricyclic lactones. In our previous report, we examined the use of alcohol nucleophiles in the Nicholas reaction. Oxidation of the alcohol functionality would enable us to study a carboxylic acid as a nucleophile in the Nicholas reaction. Thus, as outlined in Scheme 1, our goal was to convert enyne $\mathbf{1}$ into tricyclic lactone $\mathbf{4}$ using a three step sequence involving a cobalt complexation reaction, a Nicholas reaction, and a Pauson-Khand reaction.

Scheme 1. Project Goal - Tandem Nicholas/Pauson-Khand Reactions to Yield Lactone

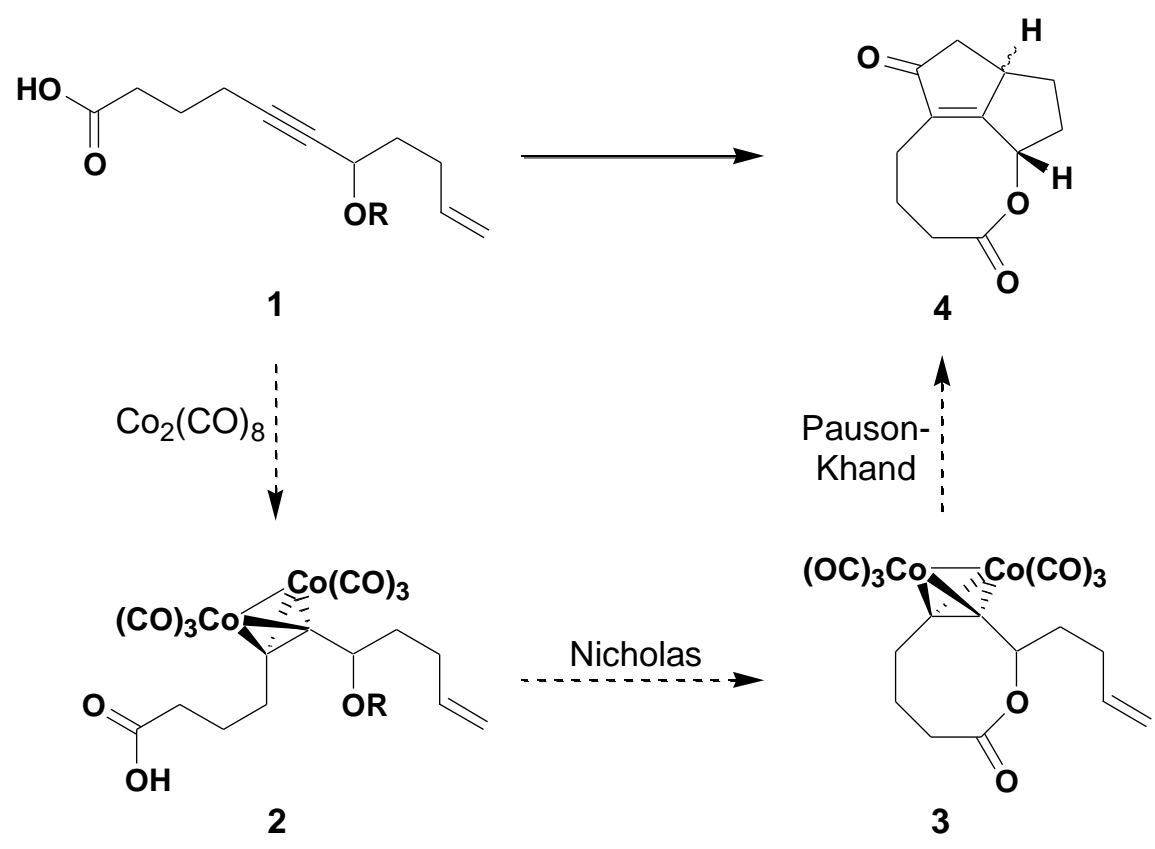

Although a seemingly straightforward modification of our cyclic ether protocol, two aspects of the lactone synthesis proved worthy of investigation. First, carboxylic acid nucleophiles are nearly unprecedented in the Nicholas reaction literature. ${ }^{2}$ We could find no examples of an intramolecular reaction incorporating a carboxylic acid and were only able to identify one example of an intermolecular transformation that used acetic acid as the nucleophile. ${ }^{3}$ In fact, propargylic esters are often used as leaving groups in Nicholas reactions, leading to the key cobalt-stabilized propargyl cations upon treatment with protic or Lewis acids. ${ }^{2}$ Second, the synthesis of medium-sized lactones is an ongoing synthetic challenge. Lactonization protocols for the synthesis of seven- to twelve-membered rings often 
yield dimeric diolides along with the medium-ring products. ${ }^{4,5}$ In some cases, only the diolides are isolated. ${ }^{4 c, 6}$ Furthermore, although numerous lactonization strategies have previously been investigated, we planned to focus on reactions with an alcohol (or ether) leaving group and a carboxylic acid nucleophile. The only comparable method is the Mitsunobu reaction, which works well to form small and large lactones but is rarely employed for the formation of medium-sized rings. ${ }^{7}$

As shown in Scheme 2, our investigation began with the synthesis of enyne acid 9 from known alkyne 5. ${ }^{8}$ Alkyne deprotonation of 5 followed by addition to 4-pentenal (6) furnished the desired alcohol 7. Methylation of 7 with sodium hydride and methyl iodide followed by THP removal with pyridinium $p$ toluenesulfonate yielded enyne $\mathbf{8}$. Conversion of primary alcohol $\mathbf{8}$ into the corresponding carboxylic acid 9 proved most efficient when using a two-step protocol involving the Dess-Martin periodinane ${ }^{9}$ and Oxone. ${ }^{10}$ Synthesis of acid 9 in one step from alcohol 8 using either the Jones reagent or pyridinium dichromate was unacceptable due to low isolated yields $(<20 \%)$.

Scheme 2. Synthesis of Enyne Acid 9.

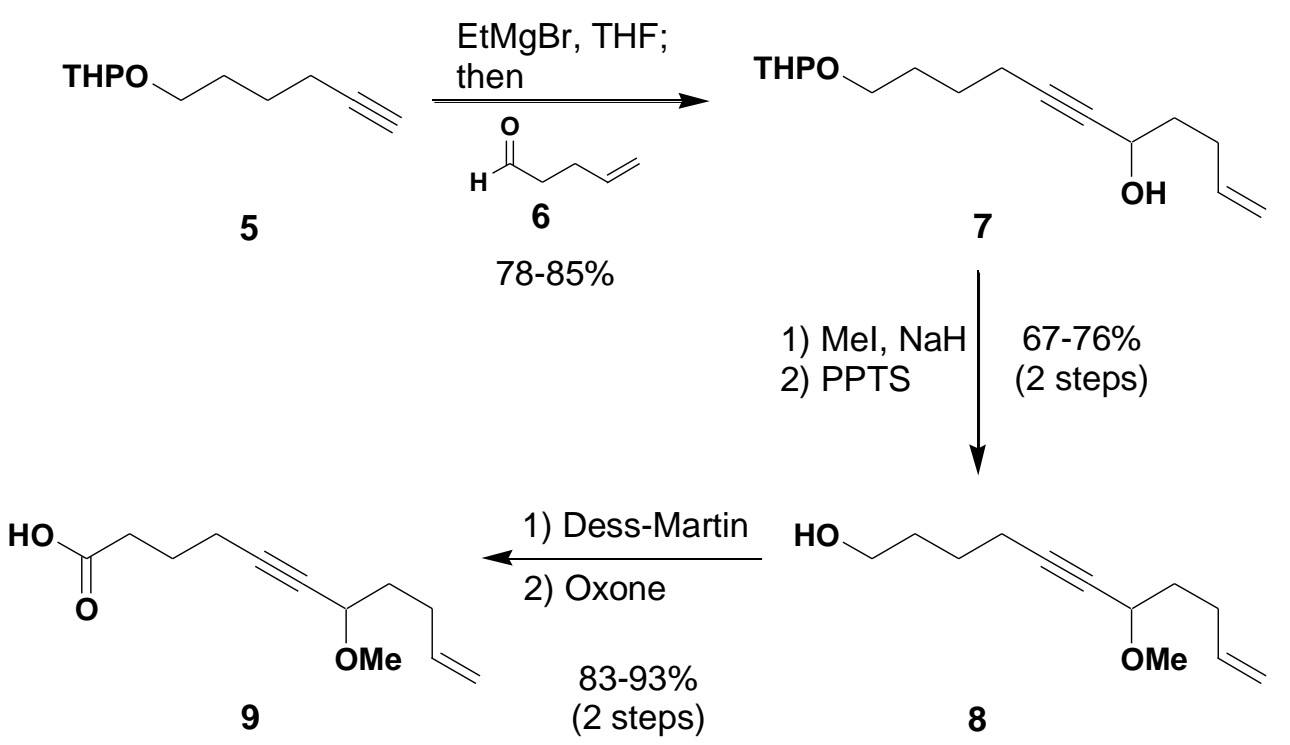

We next turned our attention to cobalt complexation of the alkyne and the key Nicholas reaction. As depicted in Scheme 3, reaction of alkyne 9 with dicobalt octacarbonyl smoothly provided cobalt-alkyne complex 10 in $86-97 \%$ yield. This material was subjected to a variety of Lewis and protic acids to determine the optimal conditions for the Nicholas reaction. Titanium tetrachloride ${ }^{11}$ promoted 
decomposition of the starting material, trimethylsilyl triflate ${ }^{12}$ yielded only trace amounts of product, and boron trifluoride-diethyl etherate ${ }^{1}$ provided at most $30 \%$ yield of product. Both protic acids investigated, triflic acid ${ }^{13}$ and tetrafluoroboric acid, ${ }^{14}$ furnished product, however, tetrafluoroboric acid was far more efficient. The optimized conditions for the Nicholas reaction involve treatment of cobaltcomplexed alkyne $\mathbf{1 0}$ with one equivalent of $\mathrm{HBF}_{4}$ at $0{ }^{\circ} \mathrm{C}$ in dichloromethane for one hour to yield 50 $63 \%$ of the diolides $\mathbf{1 1}$ and $\mathbf{1 2}$. Attempts to isolate the eight-membered ring lactone 3 proved fruitless even when we diluted the tetrafluoroboric acid reaction to a concentration of $0.004 \mathrm{M}$. Furthermore, attempts to prepare the corresponding seven- and nine-membered rings were unsuccessful. Unoptimized investigations toward the syntheses of these systems provided low yields of the fourteen- and eighteenmembered ring diolides, respectively.

Scheme 3. Cobalt Complexation and Nicholas Reaction to Yield Diolides 11 and 12.

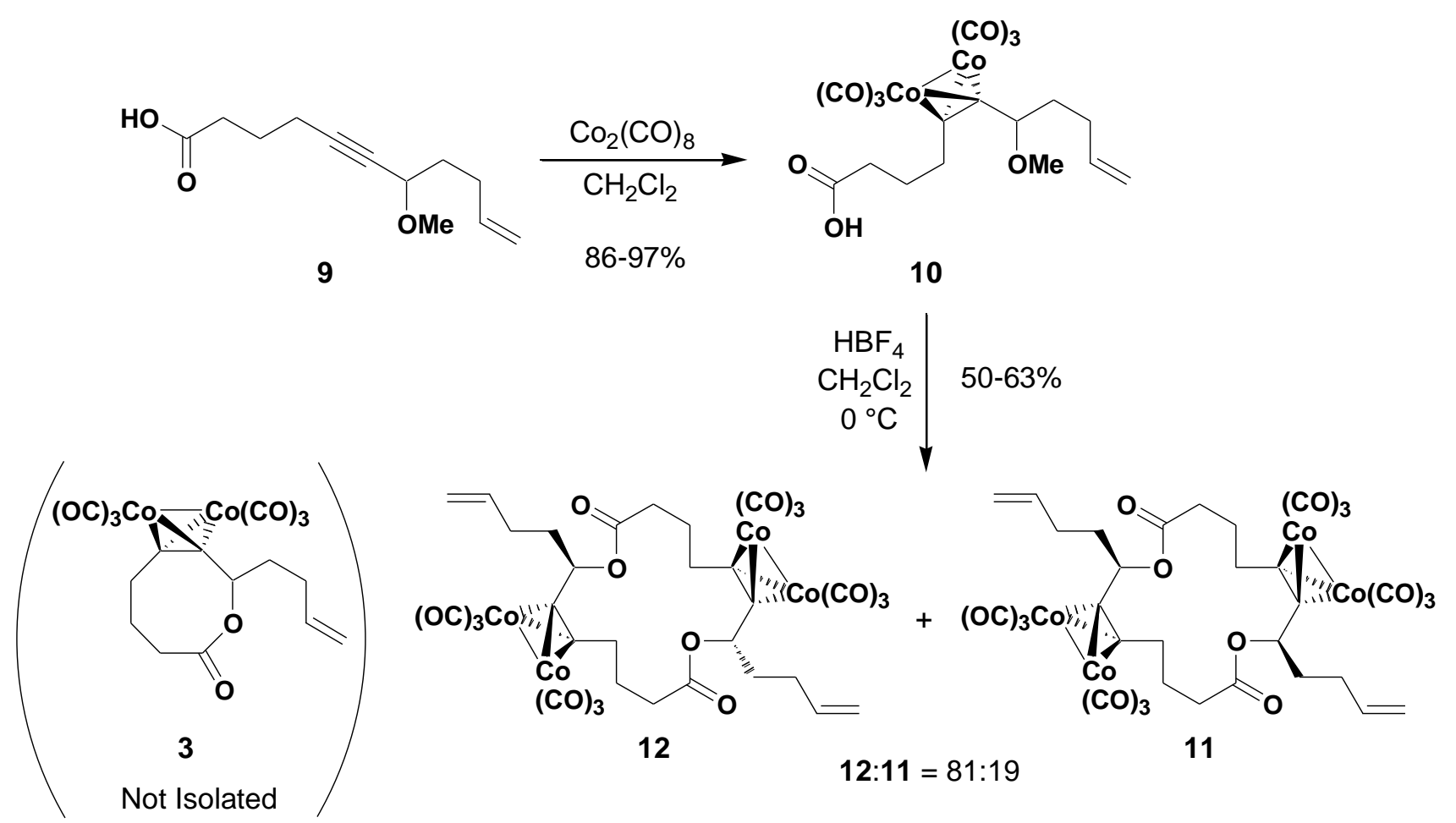

We obtained the sixteen-membered ring diolides as an 81:19 mixture of 12:11 with the anti stereoisomer 12 as the major product. Fortunately, the mixture of diolides exists as a red solid, and an X-ray quality single crystal was obtained after a variety of recrystallization attempts. ${ }^{15}$ Figure 1 shows the results of the X-ray analysis and unambiguously establishes the structure of anti isomer $\mathbf{1 2}$. The 
structural features of compound $\mathbf{1 2}$ are consistent with the results obtained by Gleiter in his study of tento fourteen-membered rings containing two cobalt-alkyne complexes. ${ }^{16,17}$ Our structure nicely demonstrates the orthogonal nature of the Co-Co bond in relation to the two carbons of the complexed triple bond, the elongated $\mathrm{C}-\mathrm{C}$ bond length of the former triple bond $(\mathrm{C} 1-\mathrm{C} 2=1.33 \AA)$, and the bent geometry of the complexed alkyne $\left(\mathrm{C} 1-\mathrm{C} 2-\mathrm{C} 3\right.$ bond angle $\left.=141^{\circ}\right)$.

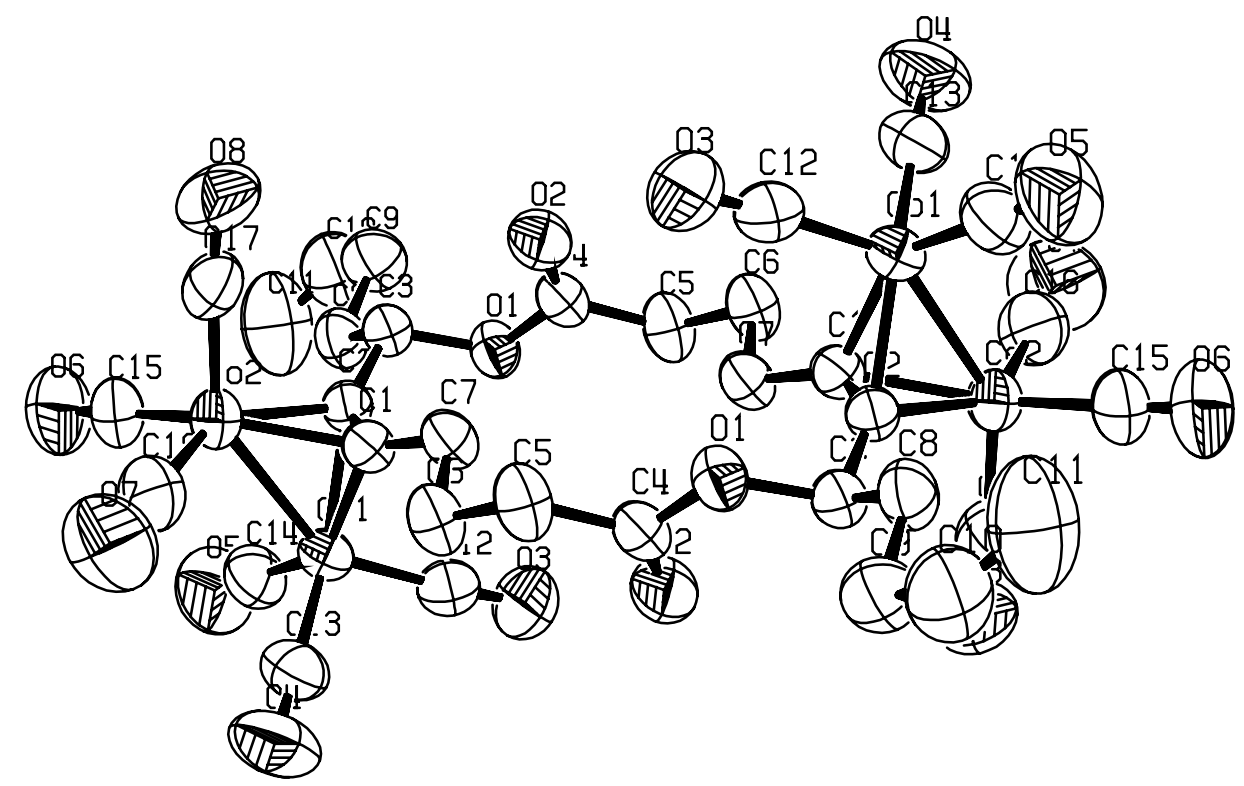

Figure 1. ORTEP view of 12, hydrogens omitted for clarity.

The outcome of the Nicholas reaction is rationalized based on product stability. Diolides are thermodynamically more stable than medium-sized lactones because of the preference for esters to adopt the $Z$ rotamer over the $E$ rotamer (with respect to the carbon-oxygen single bond of the ester). ${ }^{18}$ Thus, since our Nicholas reaction is under thermodynamic control, ${ }^{19}$ we should obtain the diolide as the only product. Our hypothesis regarding the course of the reaction is illustrated in Scheme 4. Protonated lactone 14, possessing an ester locked in the $E$ conformation, is formed as the kinetic product after production of stabilized carbocation 13. Since Nicholas reactions are run under acidic conditions, the protonated lactone can open to reform the carbocation intermediate. In a presumably slower but thermodynamically more favorable reaction, cation $\mathbf{1 3}$ can dimerize to form acyclic ester $\mathbf{1 5}$ with the ester in the preferred $Z$ conformation. This carbocation can now undergo an intramolecular Nicholas reaction to yield sixteen-memberd ring diolide $\mathbf{1 6}$ enabling both esters to adopt the favored $Z$ geometry. 
The eventual products, neutral diolides $\mathbf{1 1}$ and 12, are formed when the reaction is quenched by addition of sodium bicarbonate.

Scheme 4. Course of the Nicholas Reaction for the Formation of Diolide.

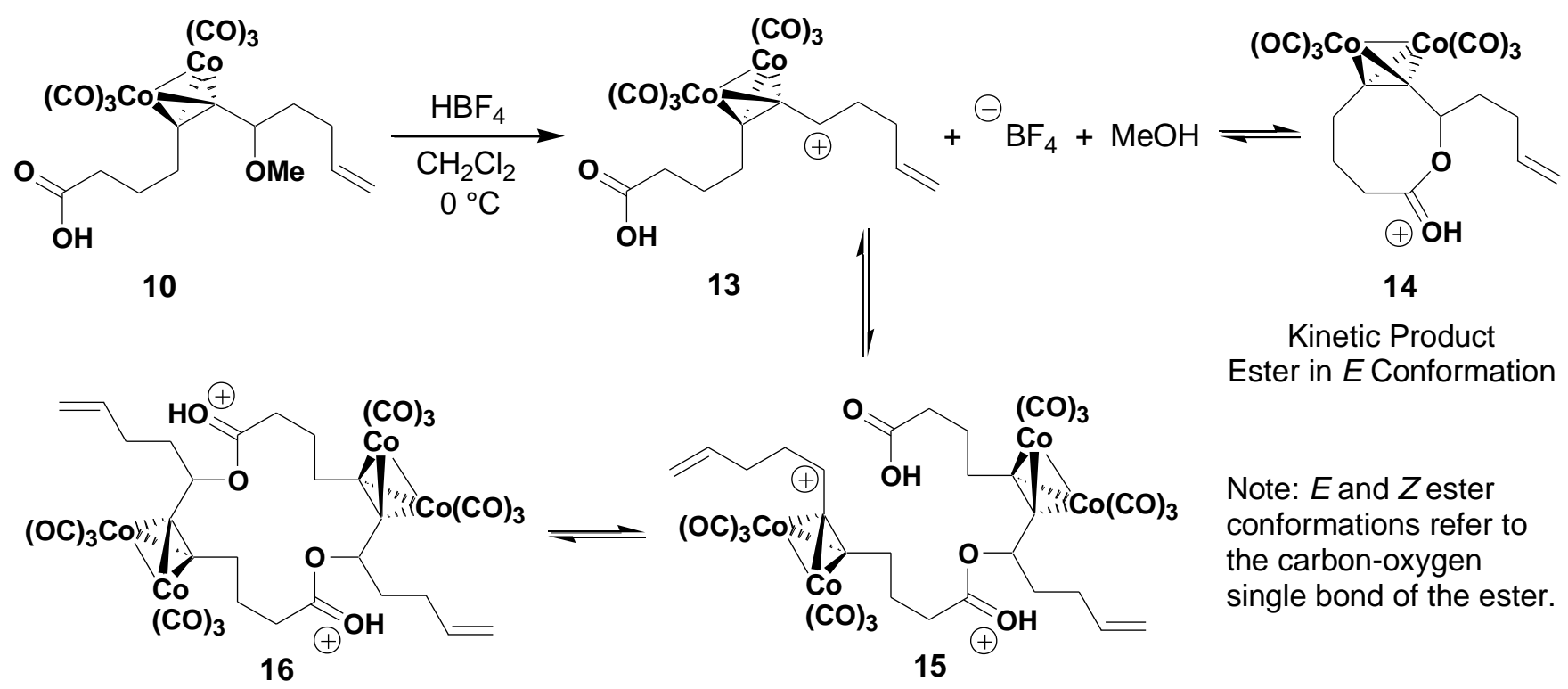

Thermodynamic Product

Both Esters in Z Conformation

Even though we were unable to isolate the eight-membered ring lactone, we were interested to explore the reactivity of the cobalt-containing diolides that we could obtain. We first subjected the mixture of diolides 11 and 12 to conditions that are known to promote the Pauson-Khand reaction. Unfortunately, exposure of 11 and 12 to $\mathrm{NMO},{ }^{20}$ cyclohexylamine, ${ }^{21}$ or heating in air ${ }^{22}$ yielded none of desired pentacyclic product 17 (see Scheme 5). These reaction conditions appeared to promote decomposition of the starting material into a complex mixture of unidentifiable byproducts.

Scheme 5. Attempted Pauson-Khand Reactions of Diolides 11 and 12.

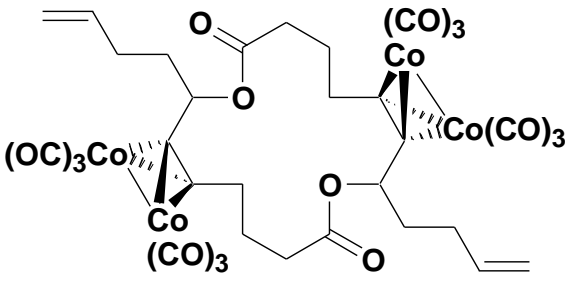

$11+12$

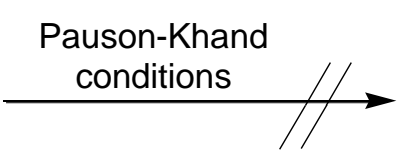<smiles>O=C1CCCC2=C3C(CCC3OC(=O)CCC2)CC(=O)C(=O)CCCC(C2=CCC3CCC2C3)O1</smiles>

17

None Observed 
We were able to remove the cobalt successfully from $\mathbf{1 1}$ and $\mathbf{1 2}$ using the standard conditions of ceric ammonium nitrate (CAN) in acetone; ${ }^{23}$ this yielded $73 \%$ of cyclic diyne $\mathbf{1 8}$ as an $81: 19$ mixture of the anti:syn diastereomers (see Scheme 6). ${ }^{24}$ Interestingly, sixteen-membered ring diyne diesters are rare in the literature. ${ }^{25}$ Cyclic diynes like 18 have proven useful in the synthesis of prismanes. ${ }^{24 d}$ Additionally, 18 possesses the cyclic carbon framework present in several natural products, e.g., halichoblelide, ${ }^{26}$ pyrenophorin, ${ }^{6}$ and elaiophylin. ${ }^{27}$

Scheme 6. Cobalt Decomplexation with CAN.
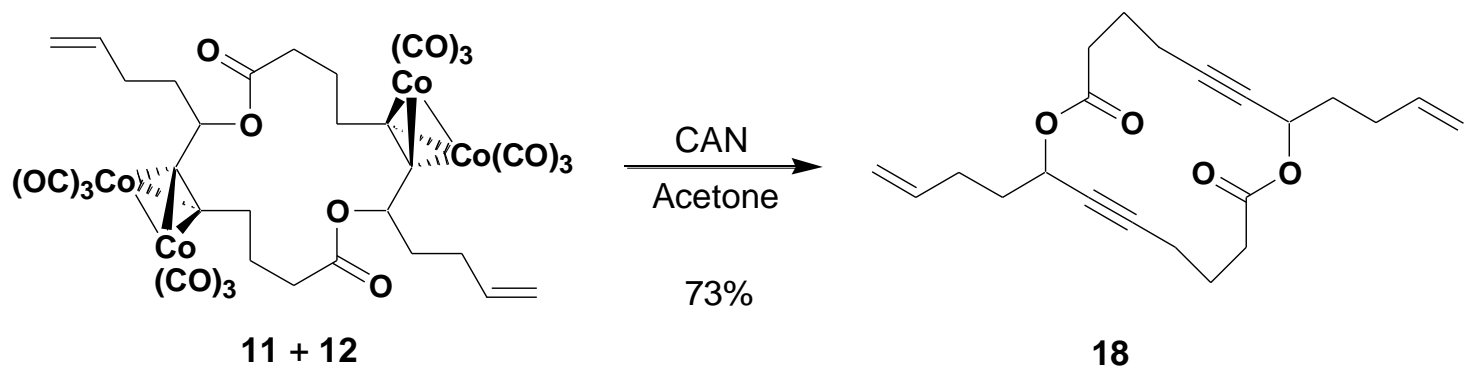

In conclusion, we have developed an efficient procedure for the synthesis of a sixteen-membered ring diolide containing two alkynes using the Nicholas reaction as the key step. Our synthesis sheds light on the utility of carboxylic acids as nucleophiles in the Nicholas reaction and suggests the reversibility of these transformations for the synthesis of a medium-sized ring. We have also obtained an X-ray crystal structure of the sixteen-membered ring diolide incorporating two cobalt-complexed alkynes.

\section{Experimental Section}

7-Methoxy-undec-10-en-5-ynoic acid (9). A flame dried, two-necked, round-bottomed flask equipped with a septum and gas inlet adapter was placed under a nitrogen atmosphere and charged with the Dess-Martin periodinane (1.20 g, $2.84 \mathrm{mmol}, 1.2 \mathrm{eq})$ and $7 \mathrm{~mL}$ of $\mathrm{CH}_{2} \mathrm{Cl}_{2}$ to yield a cloudy, white suspension. Compound $\mathbf{8}^{1}$ (464 mg, $2.36 \mathrm{mmol}$ ) was dissolved in $2 \mathrm{~mL}$ of $\mathrm{CH}_{2} \mathrm{Cl}_{2}$ and transferred to the reaction flask via cannula. The resulting clear, colorless solution was stirred at room temp for $2 \mathrm{~h}$. The reaction mixture was diluted with $15 \mathrm{~mL}$ of ether to yield white precipitate. This suspension was added to a solution of $4.5 \mathrm{~g}$ of $\mathrm{Na}_{2} \mathrm{~S}_{2} \mathrm{O}_{3}$ in $23 \mathrm{~mL}$ of saturated $\mathrm{NaHCO}_{3}$ and stirred for $5 \mathrm{~min}$. The aqueous layer was removed and the organic phase was washed with saturated $\mathrm{NaHCO}_{3}$ and water, dried over 
$\mathrm{MgSO}_{4}$, filtered and concentrated to yield $445 \mathrm{mg}(97 \%)$ of the aldehyde as a clear, colorless oil. This material (445 mg, $2.29 \mathrm{mmol}$ ) was transferred to a round-bottomed flask equipped with a septum and gas inlet needle and placed under a nitrogen atmosphere. DMF (23 mL) and Oxone (1.41 g, $2.29 \mathrm{mmol})$ were added to the reaction flask to yield a clear, colorless solution that was allowed to stir overnight at room temperature. The resulting cloudy white suspension was added to a mixture of $45 \mathrm{~mL}$ of $1 \mathrm{M} \mathrm{HCl}$ and $40 \mathrm{~mL}$ of EtOAc. The aqueous layer was separated and extracted with EtOAc. The combined organic layers were washed with $1 \mathrm{M} \mathrm{HCl}$ and brine, dried over $\mathrm{MgSO}_{4}$, filtered, and concentrated to yield $455 \mathrm{mg}$ (94\%, 91\% over two steps) of 9 as a clear, colorless oil; IR (neat) 3500-2500, 2232, 1718 , $1641 \mathrm{~cm}^{-1} ;{ }^{1} \mathrm{H}$ NMR (400 MHz, $\left.\mathrm{CDCl}_{3}\right) \delta 11.0$ (br s, 1H) 5.85-5.75 (m, 1H), $5.03(\mathrm{dq}, J=17.0,1.7 \mathrm{~Hz}$, 1H), 4.97 (br d, $J=9.9 \mathrm{~Hz}, 1 \mathrm{H}), 3.92(\mathrm{tt}, J=6.6,1.8 \mathrm{~Hz}, 1 \mathrm{H}), 3.37(\mathrm{~s}, 3 \mathrm{H}), 2.50(\mathrm{t}, J=7.3 \mathrm{~Hz}, 2 \mathrm{H})$, $2.32(\mathrm{td}, J=7.0,1.8 \mathrm{~Hz}, 2 \mathrm{H}), 2.19(\mathrm{q}, J=7.3 \mathrm{~Hz}, 2 \mathrm{H}), 1.88-1.68(\mathrm{~m}, 4 \mathrm{H}) ;{ }^{13} \mathrm{C}$ NMR $(100 \mathrm{MHz}$, $\left.\mathrm{CDCl}_{3}\right): \delta 179.5,137.9,115.1,85.1,79.8,70.8,56.3,35.0,32.9,29.6,23.6,18.2 ; \mathrm{HRMS}-\mathrm{EI}: m / z\left[\mathrm{M}^{+}\right]$ calcd for $\mathrm{C}_{12} \mathrm{H}_{18} \mathrm{O}_{3}, 210.1256$; found 210.1303 .

7-Methoxy-undec-10-en-5-ynoic acid hexacarbonyl dicobalt complex (10). A flame dried, roundbottomed flask equipped with a septum and gas inlet needle was charged with alkyne 9 (253 mg, 1.20 mmol) and placed under a nitrogen atmosphere. $\mathrm{CH}_{2} \mathrm{Cl}_{2}(2.5 \mathrm{~mL})$ was added followed by $\mathrm{Co}_{2}(\mathrm{CO})_{8}$ (494 mg, $1.44 \mathrm{mmol}, 1.2 \mathrm{eq}$ ) to yield a dark red/black solution that was stirred at room temp for $30 \mathrm{~min}$. A second portion of $\mathrm{Co}_{2}(\mathrm{CO})_{8}(165 \mathrm{mg}, 0.481 \mathrm{mmol}, 0.4 \mathrm{eq})$ was added and the reaction was allowed to stir at room temp for an additional $30 \mathrm{~min}$. The reaction mixture was added directly to a $60 \mathrm{~g}$ silica gel column eluting with $10-35 \%$ ether in pet. ether to afford $577 \mathrm{mg}(97 \%)$ of 10 as a thick red oil; IR (neat) 3081, 2977, 2932, 2826, 2089, 2046, 2015, $1710 \mathrm{~cm}^{-1} ;{ }^{1} \mathrm{H}$ NMR (400 MHz, $\left.\mathrm{CDCl}_{3}\right) \delta 5.85-5.81(\mathrm{~m}$, 1H), 5.09-5.00 (m, 2H), 4.28-4.26 (m, 1H), 3.82 (br s, 2H), $3.51(\mathrm{~s}, 3 \mathrm{H}), 2.91$ (br s, 2H), 2.33-2.25 (m, $2 \mathrm{H}), 2.03-1.73(\mathrm{~m}, 2 \mathrm{H}), 1.25-1.20(\mathrm{~m}, 2 \mathrm{H})$ (Note: the carboxylic acid peak is not visible); ${ }^{13} \mathrm{C}$ NMR $\left(100 \mathrm{MHz}, \mathrm{CDCl}_{3}\right) \delta 200.0,137.8,115.5,98.6,98.3,81.1,58.8,37.1,34.7$ (very broad), 30.4 (Note: 4 peaks coincidentally overlap). 
complex (11 and 12). A flame dried round-bottomed flask equipped with a septum and gas inlet adapter was charged with acid $10(577 \mathrm{mg}, 1.16 \mathrm{mmol})$ and placed under a nitrogen atmosphere. $\mathrm{CH}_{2} \mathrm{Cl}_{2}$ was added and the resulting dark red/black solution was cooled at $0{ }^{\circ} \mathrm{C} . \mathrm{HBF}_{4}(54 \%$ in ether, $0.160 \mathrm{~mL}, 1.16$ mmol) was added and the reaction mixture was stirred at $0{ }^{\circ} \mathrm{C}$ for $1 \mathrm{~h}$. The reaction was quenched while still cold by addition of $15 \mathrm{~mL}$ of saturated $\mathrm{NaHCO}_{3}$. The aqueous layer was removed and the organic phase was dried over $\mathrm{MgSO}_{4}$ and added to a sintered glass funnel packed with silica gel. Rinsing with $400 \mathrm{~mL}$ of $\mathrm{CH}_{2} \mathrm{Cl}_{2}$ furnished $269 \mathrm{mg}$ (50\%) of diolides 11 and 12 as a bright red/orange solid; mp 124 $125^{\circ} \mathrm{C}$ (dec.); IR (KBr) 2972, 2934, 2090, 2055, 2019, $1734 \mathrm{~cm}^{-1} ;{ }^{1} \mathrm{H}$ NMR (400 MHz, $\left.\mathrm{CDCl}_{3}\right) \delta 6.10$ (dd, $J=10.1,3.1 \mathrm{~Hz}, 2 \mathrm{H}-$ minor isomer), $5.96(\mathrm{t}, J=6.5 \mathrm{~Hz}, 2 \mathrm{H}-$ major isomer), 5.88-5.78 (m, $2 \mathrm{H})$, 5.07-5.01 (m, 4H), 2.96-2.89 (m, 2H - minor isomer), 2.70-2.63 (m, 4H), 2.49-1.91 (m, 14H), 1.84-1.79 $(\mathrm{m}, 2 \mathrm{H}) ;{ }^{13} \mathrm{C}$ NMR $\left(100 \mathrm{MHz}, \mathrm{CDCl}_{3}\right) \delta 199.6,172.5,172.2,137.1,137.0,115.8,100.1,98.9,96.0$ 95.2, 73.2, 72.0, 53.4, 35.9, 34.9, 34.1, 33.6, 33.3, 33.1, 32.8, 30.3, 30.2, 30.1, 29.7, 25.9, 25.3, 22.4, 14.2; HRMS-FAB: $m / z[\mathrm{M}+\mathrm{H}]^{+}$calcd for $\mathrm{C}_{34} \mathrm{H}_{29} \mathrm{Co}_{4} \mathrm{O}_{16}, 928.8784$; found 928.8719 .

8,16-Di-but-3-enyl-1,9dioxa-cyclohexadeca-6,14-diyne-2,10-dione (18). A round-bottomed flask was charged with diolides 11 and $12(53 \mathrm{mg}, 0.0534 \mathrm{mmol})$ and $12 \mathrm{~mL}$ of acetone to yield a red suspension. The reaction flask was cooled at $0{ }^{\circ} \mathrm{C}$ and eight portions of CAN (59 $\mathrm{mg}, 0.107 \mathrm{mmol}$ for each portion) were added over 5 min. The cooling bath was removed and the reaction was allowed to stir at room temp for $4 \mathrm{~h}$. The resulting yellow/orange suspension was concentrated to yield a yellow solid that was transferred to a flask containing $\mathrm{CH}_{2} \mathrm{Cl}_{2}$ and water. The organic layer was separated, dried over $\mathrm{MgSO}_{4}$, and concentrated to yield $21 \mathrm{mg}$ of a yellow oil that was deposited on $40 \mathrm{mg}$ of silica gel and added to a $2 \mathrm{~g}$ silica gel column eluting with 5\% ether in pet. ether to afford $14 \mathrm{mg}(73 \%)$ of 18 as a white film; IR (neat) 3077, 2932, 2851, 2241, 1740, $1641 \mathrm{~cm}^{-1} ;{ }^{1} \mathrm{H}$ NMR (400 MHz, $\mathrm{CDCl}_{3}$ ) $\delta$ (major isomer only) $5.85-5.74(\mathrm{~m}, 2 \mathrm{H}), 5.35(\mathrm{t}, J=6.8 \mathrm{~Hz}, 2 \mathrm{H}), 5.06(\mathrm{dd}, J=17.0,1.5 \mathrm{~Hz}, 2 \mathrm{H}), 4.98$ $(\mathrm{d}, J=10.3 \mathrm{~Hz}, 2 \mathrm{H}), 2.59-2.42(\mathrm{~m}, 6 \mathrm{H}), 2.29-2.14(\mathrm{~m}, 6 \mathrm{H}), 1.96-1.70(\mathrm{~m}, 8 \mathrm{H}) ;{ }^{13} \mathrm{C} \mathrm{NMR}(100 \mathrm{MHz}$ $\left.\mathrm{CDCl}_{3}\right) \delta$ (major isomer only) 172.4, 137.3, 115.5, 84.7, 79.8, 63.9, 33.9, 32.0, 29.4, 22.0, 17.6. 
Acknowledgment. We thank Research Corporation and Smith College for generous financial support. M.M.Q. would like to thank Pfizer for a summer undergraduate research fellowship. We thank Dr. Charles Amass, Dr. A. Chandrasekaran, and Dr. Stephen J. Eyles for assistance with NMR, X-ray, and MS experiments, respectively.

Supporting Information Available: General experimental details, ${ }^{1} \mathrm{H}$ NMR spectra for compounds

9-12 and 18, and X-ray crystallographic data for 12. This material is available free of charge via the Internet at http://pubs.acs.org.

\section{Table of Contents Graphic:}

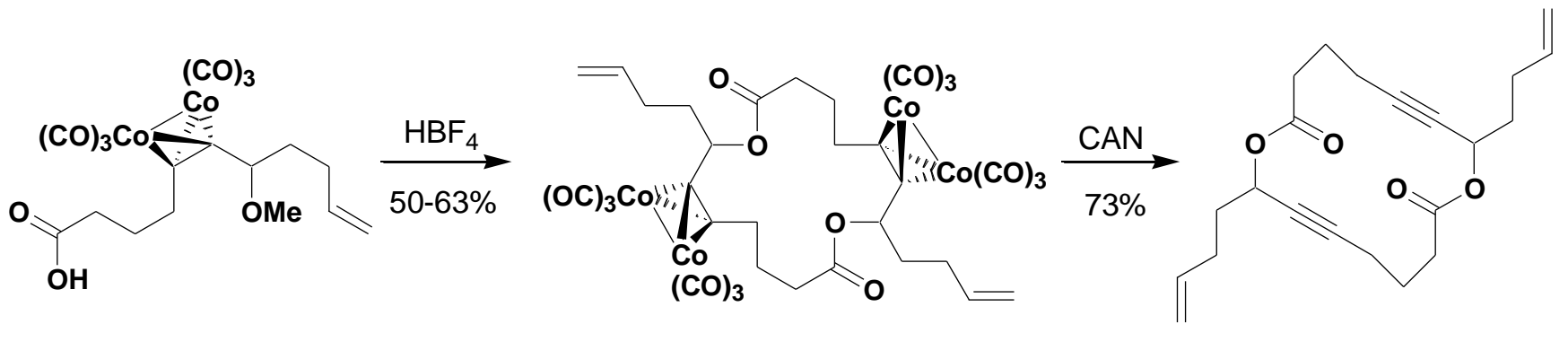

${ }^{1}$ Quintal, M. M.; Closser, K. D.; Shea, K. M. Org. Lett. 2004, 6, 4949-4952.

${ }^{2}$ For reviews, see a) Teobald, B. J. Tetrahedron 2002, 58, 4133-4170. b) Green, J. R. Curr. Org. Chem. 2001, 5, 809-826. c) Caffyn, A. J. M.; Nicholas, K. M. In Comprehensive Organometallic Chemistry II; Abel, E. W., Stone, F. G. A., Wilkinson, G., Eds.; Pergamon: Kidlington, 1995; Vol. 12, 685-702.

${ }^{3}$ Betancort, J. M.; Rodriguez, C. M.; Martin, V. S. Tetrahedron Lett. 1998, 39, 9773-9776.

${ }^{4}$ (a) Christoffers, J.; Oertling, H.; Fischer, P.; Frey, W. Tetrahedron 2003, 59, 3769-3778. (b) Shiina, I.; Mukaiyama, T. Chem. Lett. 1994, 677-680. (c) Mukaiyama, T.; Izumi, J.; Miyashita, M.; Shiina, I. Chem. Lett. 1993, 907-910. (d) White, J. D.; Green, N. J.; Fleming, F. F. Tetrahedron Lett. 1993, 34, 3515-3518.

${ }^{5}$ For procedures that minimize or eliminate diolide formation, see: (a) Kinoshita, H.; Shinokubo, H.; Oshima, K. Angew. Chem. Int. Ed. 2005, 44, 2397-2400. (b) Molander, G. A.; Dehmel, F. J. Am. Chem. Soc. 2004, 126, 10313-10318. (c) Ashfeld, B. L.; Miller, K. A.; Martin, S. F. Org. Lett. 2004, 6, 1321-1324. (d) Ishihara, K.; Kubota, M.; Kurihara, H.; Yamamoto, H. J. Org. Chem. 1996, 61, 4560-4567. 
${ }^{6}$ Lee, C. W.; Grubbs, R. H. J. Org. Chem. 2001, 66, 7155-7158.

${ }^{7}$ For a review, see Hughes, D. L. Org. Prep. Proced. Int. 1996, 28, 127-164.

${ }^{8}$ Synthesized in one step from the commercially available alcohol according to Marino, J. P.; Nguyen, H. N. J. Org. Chem. 2002, 67, 6291-6296.

${ }^{9}$ Dess, D. B.; Martin, J. C. J. Am. Chem. Soc. 1991, 113, 7277-7287.

${ }^{10}$ Travis, B. R.; Sivakumar, M.; Hollist, G. O.; Borhan, B. Org. Lett. 2003, 5, 1031-1034.

${ }^{11}$ Magnus, P.; Eisenbeis, S. A.; Fairhurst, R. A.; Iliadis, T.; Magnus, N. A.; Parry, D. J. Am. Chem. Soc. 1997, 119, 55915605.

12 Jamison, T. F.; Shambayati, S.; Crowe, W. E.; Schreiber, S. L. J. Am. Chem. Soc. 1994, 116, 5505-5506.

${ }^{13}$ Takase, M.; Morikawa, T.; Abe, H.; Inouye, M. Org. Lett. 2003, 5, 625-628.

${ }^{14}$ (a) Mohamed, A. B.; Green, J. R.; Masuda, J. Synlett 2005, 1543-1546. (b) Roth, K.-D.; Müller, U. Tetrahedron Lett. 1993, 34, 2919-2922.

15 The optimal recrystallization technique involved liquid-liquid diffusion of dichloromethane and diethyl ether in a $5 \mathrm{~mm}$ NMR tube over three days at room temperature.

${ }^{16}$ Rausch, B. J.; Gleiter, R.; Rominger, F. J. Chem. Soc., Dalton Trans. 2002, 2219-2226.

${ }^{17}$ For other examples of cyclic molecules containing two cobalt-complexed alkynes that have been studied by X-ray crystallography, see: (a) Werz, D. B.; Schulte, J. H.; Rausch, B. J.; Gleiter, R.; Rominger, F. Eur. J. Inorg. Chem. 2004, 2585-2593. (b) Golovko, V. B.; Hope-Weeks, L. J.; Mays, M. J.; McPartlin, M.; Sloan, A. M.; Woods, A. D. New. J. Chem. 2004, 28, 527-534. (d) Schaefer, C.; Gleiter, R.; Rominger, F. Eur. J. Org. Chem. 2003, 3051-3059. (e) Bennett, S. C.; Jeffery, J. C.; Went, M. J. J. Chem. Soc., Dalton Trans. 1994, 3171-3176. (f) Gelling, A.; Mohmand, F.; Jeffery, J. C.; Went, M. J. J. Chem. Soc., Dalton Trans. 1993, 1857-1862. (g) Cragg, R. H.; Jeffery, J. C.; Went, M. J. J. Chem. Soc., Chem. Commun. 1990, 993-994.

18 (a) Wiberg, K. B.; Laidig, K. E. J. Am. Chem. Soc. 1985, 109, 5935-5943. (b) Deslongchamps, P. Stereoelectronic Effects in Organic Chemistry; Pergamon: New York, 1983; pp 54-67. 
${ }^{19}$ For examples of Nicholas reactions to form cyclic ethers under thermodynamic control, see: (a) Liu, T.-Z.; Li, J.-M.; Isobe, M. Tetrahedron 2000, 56, 10209-10219. (b) Yenjai, C.; Isobe, M. Tetrahedron 1998, 54, 2509-2520.

${ }^{20}$ Shambayati, S.; Crowe, W. E.; Schreiber, S. L. Tetrahedron Lett. 1990, 31, 5289-5292.

${ }^{21}$ Sugihara, T.; Yamada, M.; Ban, H.; Yamaguchi, M.; Kaneko, C. Angew. Chem., Int. Ed. Engl. 1997, 36, 2801-2804.

${ }^{22}$ Jamison, T. F.; Shambayati, S.; Crowe, W. E.; Schreiber, S. L. J. Am. Chem. Soc. 1997, 119, 4353-4363.

${ }^{23}$ Cirsóstomo, F. R. P.; Martin, T.; Martin, V. S. Org. Lett. 2004, 6, 565-568.

${ }^{24}$ For reports of other 16-membered ring cyclic diynes, see: (a) Hellbach, B.; Gleiter, R.; Rominger, F. Synthesis 2003, 25352541. (b) Boss, C.; Keese, R. Tetrahedron 1997, 53, 3111-3122. (c) Gleiter, R.; Merger, M. Synthesis 1995, 969-972. (d) Gleiter, R.; Ohlbach, F. J. Chem. Soc., Chem. Commun. 1994, 2049-2050.

${ }^{25}$ Padwa, A.; Chiacchio, U.; Fairfax, D. J.; Kassir, J. M.; Litrico, A.; Semones, M. A.; Xu, S. L. J. Org. Chem. 1993, 58, 6429-6437.

${ }^{26}$ Yamada, T.; Minoura, K.; Numata, A. Tetrahedron Lett. 2002, 43, 1721-1724.

${ }^{27}$ Hammann, P.; Kretzschmar, G. Tetrahedron 1990, 46, 5609-5616. 